\title{
Thermo-kinetic Modelling and Analysis of the Simultaneous Hot Stamping and Quenching of EN AW-6016-T4 Sheet
}

\author{
Manoj Kumar \\ LKR Leichtmetallkompetenzzentrum Ranshofen $\mathrm{GmbH}$, Austrian Institute of Technology, \\ Lamprechtshausnerstrasse 61, postfach 26, 5282, Ranshofen, Austria \\ manoj.kumar@ait.ac.at
}

Keywords: AW-6016, forming, quenching, paint bake response, MatCalc

\begin{abstract}
The aluminium alloy AW-6016-T4 sheet is the most widely used alloy for simple-shape outer body parts for passenger vehicles at room temperature. However, for complex parts, such as the B-pillar, the room temperature formability of AW-6016-T4 sheet is not sufficient. Simultaneous hot stamping and quenching is a viable alternative, but there is still limited information about the influence of process parameters on both the formability during the process and the part strength at the end of the process. A combination of thermo-kinetic simulation and experiments were used to investigate the influence of process parameters in the simultaneous hot stamping and quenching process.

Increasing the heating rate from 1 to $100 \mathrm{~K} \mathrm{~s}^{-1}$ during heating to the solution heat treatment (SHT) temperature was found to have no significant influence on the UTS. However, a SHT time of 4 min is required to achieve highest strength by the end of the process chain. Increasing the amount of deformation and cooling rate after SHT have a positive influence on the finished part. Predicted DSC curves and Yield strength values from MatCalc were in good agreement with the experimental results.
\end{abstract}

\section{Introduction}

The AW-6016 alloy has adequate formability such as drawing depth and paint bake response during the cold stamping processing chain for the production of simple geometry parts. This is the reason it is the most preferred material in manufacturing automotive outer body components in Europe. However, for production of complex geometry crash relevant parts - including the bumper and B-pillar - room temperature formability of AA6016 is not sufficient in conventional cold stamping.

To improve the room temperature formability, research into the forming of AW-6016 into complex structural parts has focused on the simultaneous hot stamping and quenching process [1]. However, there is still limited knowledge on the effect of the processing parameters on the mechanical properties of the finished product.

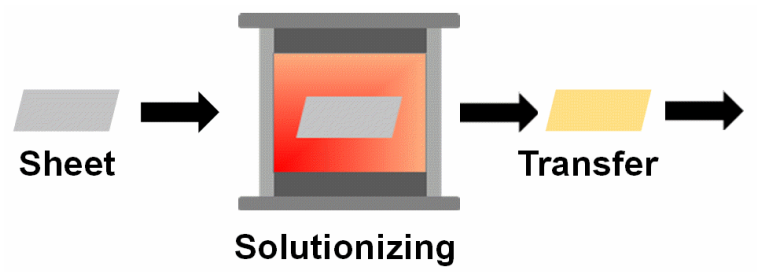

(1)

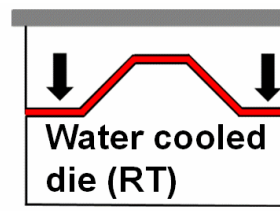

Forming

(2)

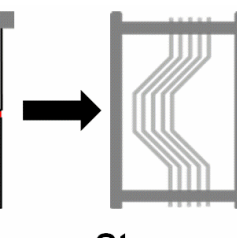

Storage

(3)

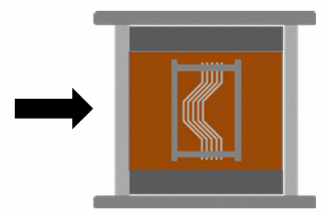

Paint baking

(4)

Fig. 1. A simple schematic representation of the process steps in the hot stamping process chain.

The hot stamping and quenching process chain mainly consists of (1) Solution heat treatment of the sheet and quick transfer into the press, (2) forming and die quenching, (3) storage and (4) paint baking, as shown in Fig. 1. For the simultaneous hot stamping and quenching process, formability during processing and the final part quality depend on the heating rate, solution heat treatment 
temperature and time, amount of deformation and quenching rate, and the paint baking heat treatment. The paint baking heat treatment is a fixed process - i.e. $185^{\circ} \mathrm{C}$ for $20 \mathrm{~min}$. Therefore, this paper investigates the influence of the solutionizing, heating rate, pre-deformation and cooling rate on the final part mechanical properties of the AW-6016 alloy in order to optimize the process window for the simultaneous hot stamping and quenching process. During processing the precipitation state of the age hardenable AW-6016 changes with each processing step.

A comprehensive understanding of the hot stamping and quenching process leads to optimization of the process window and was developed as follow. Endothermic and exothermic peaks from differential scanning calorimeter (DSC) temperature vs. heat flow plots - corresponding to the dissolution and formation of precipitate, respectively [2] - were used to calibrate the thermo-kinetic model [3-6] in order to predict the yield strength at each stage of the process chain. These results were then compared to data from deformation dilatometer experiments simulating the process chain.

\section{Experimental}

AW-6016-T4 sheet in the as-rolled condition with a thickness of $1.5 \mathrm{~mm}$ and chemical composition (in wt. \%) of $1.1 \mathrm{Si}, 0.38 \mathrm{Fe}, 0.12 \mathrm{Cu}, 0.13 \mathrm{Mn}, 0.31 \mathrm{Mg}, 0.02 \mathrm{Zn}, 0.003 \mathrm{Ni}, 0.02 \mathrm{Cr}$, $0.03 \mathrm{Ti}, 0.002 \mathrm{Zr}$ and rest $\mathrm{Al}$ was used in the current work. This sheet was solution heat treated and water quenched to introduce a W-temper into the sheet. Thereafter, a heat treatment - i.e. $205^{\circ} \mathrm{C} / 1 \mathrm{~h}$ - was also performed on some of the sheets to develop an artificial aging temper. DSC samples were prepared from the AW-6016 sheets in the three tempers (T4, W and artificially aged) described above. Each DSC sample was tested in a Netzsch-DSC 204 F1 using a continuous heating rate of $10 \mathrm{~K} \mathrm{~min}^{-1}$ up to $600^{\circ} \mathrm{C}$. These results provided information about the precipitation state in the various tempers.

Tensile samples with a gauge length of $10 \mathrm{~mm}$ and width of $3 \mathrm{~mm}$ were machined from the AW6016-T4 sheet along the direction of rolling. These samples were tested according to the parameters described in Fig.2 to assess the optimum heating rate (Fig. 2(a)), solution heat treatment time (Fig.2(b \& c)) and influence of deformation and cooling rate (Fig.2(d)), respectively. Tensile tests at $560{ }^{\circ} \mathrm{C}$ with strain rate of $1 \mathrm{~s}^{-1}$ and thermo-mechanical treatments as shown in Fig. 2(a \& b) and (Fig. 2(c \& d)) were performed in Bähr deformation dilatometer. However, tensile tests at room temperature as shown in Fig. 2(c \& d) were performed in a ZWICK/Z100 at an initial strain rate of $2 \times 10^{-3} \mathrm{~s}^{-1}$.Tests were repeated at least three times to ensure reproducibility.

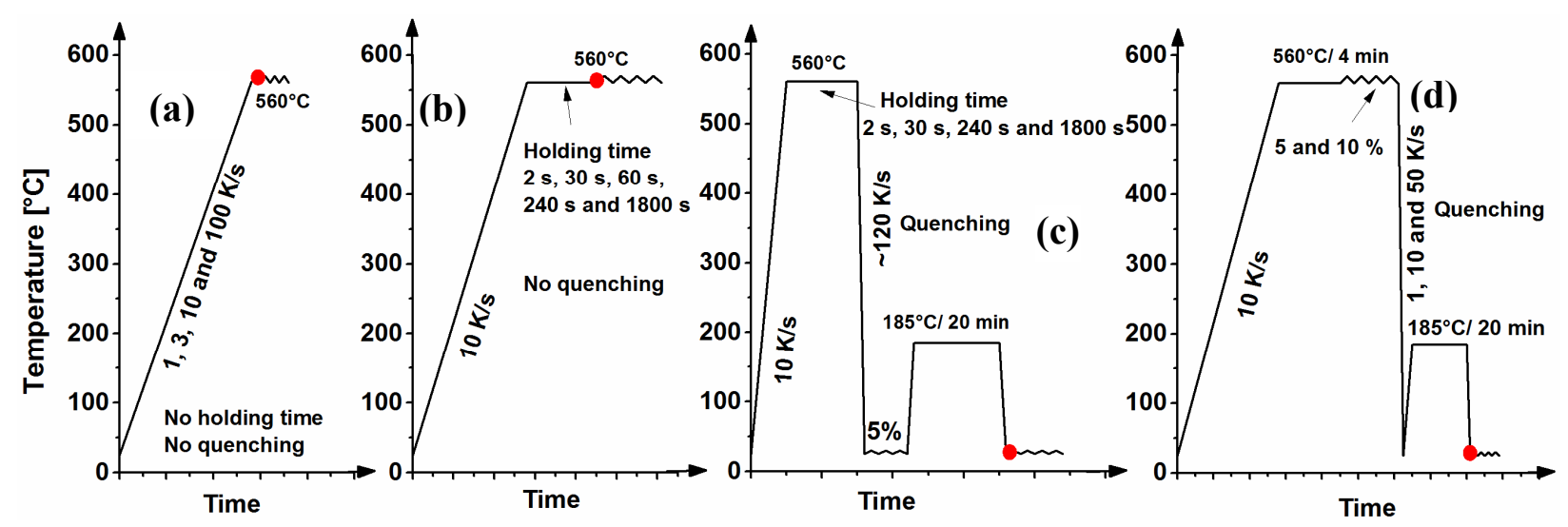

Fig.2. The test parameters to assess the optimum (a) heating rate, (b \& c) solution heat treatment time and influence of (d) deformation and quenching. The zigzag lines in each of the figures show the deformation steps, including the tensile test at the end. The solid red circles show the starting point of tension tests. 


\section{Thermo-kinetic Modelling}

During the simultaneous deformation and quenching process, the generation and annihilation of dislocations and vacancies occur in parallel with dynamic precipitation. Rack [9] investigated the deformation effect on the artificial ageing of AW-6061 and found that the most important effect of prior deformation lies in its ability to increase the nucleation rate of precipitating phases. This occurs by decreasing the volume strain energy change contribution to the Gibbs free energy necessary for the formation of a critical nucleus. Using the physical models available Sherstnev et al. [10] proposed a physical model based on a simple one parameter dislocation density evolution model by Kock [11] coupled with the deformation induced vacancies formation model by Stüwe [12]. This has been incorporated in the MatCalc software as a one-parameter ABC model.

Quenching results in an excess concentration of vacancies dependent on the cooling rate. Fischer et al. [13] have modelled the generation and annihilation kinetics of excess vacancies in aluminium alloys. They considered that the excess vacancies gradually annihilate at available sinks represented by jogs at dislocations, grain boundaries or free surfaces. This model is widely known as the Fischer-Svboda-Appel-Kozeschnik (FSAK) model. The excess vacancies are considered to enhance the diffusional mobility of solute atoms, hence influencing the nucleation and growth of precipitates during isothermal and non-isothermal heat treatments. Lang et al. [14] utilized the FSAK model in the MatCalc software to understand the influence of cooling rate on the evolution of the precipitate microstructure in AW-6xxx alloys. They showed increasing the cooling rate produces a faster precipitation and a higher early precipitate phase fraction during natural aging due to an increasing concentration of excess vacancies with increasing cooling rate.

The thermo-kinetic modelling of a precipitation hardening alloy during the simultaneous deformation and quenching process is based on describing the evolution of the precipitate microstructure in the material and its sensitivity to the generation of dislocations and quenched-invacancies. Svoboda et al. [7] have developed a physical model to describe the evolution of the precipitate microstructure by applying the thermodynamic extremum principle. This principle postulates that a thermodynamic system changes in the direction of maximum Gibbs free energy reduction. The reduction in energy occurs by migration of interfaces, diffusion of all components in the precipitates, and diffusion of all components in the matrix. These are quantitatively described by the interface mobilities, diffusion coefficients within the precipitates and diffusion coefficient in the matrix, respectively. This model is widely known as the Svoboda-Fischer-Fratzl-Kozeschnik (SFFK) mean-field model and is implemented in the MatCalc software [8]. Based on the chemical composition of an alloy and the temperature of the system, the calculation of the thermodynamics of the multi-component system is made using CALPHAD type databases. These provide chemical potentials of the phases as well as diffusivities of the elements involved [6]. The potential of the SFFK model may be summarised as follows.

a. The model is applicable to simulations of all classical stages of evolution of the precipitate microstructure - i.e., nucleation, growth and coarsening.

b. The model accounts for the evolution of the total number of precipitates and the size and mean chemical composition of each precipitate and the matrix.

c. The model can describe the interaction of a large number of precipitates with different chemical compositions and different sizes via diffusion in the matrix.

d. It also accounts for the misfit effect between the precipitates and the matrix and for the influence of the chemical composition on the stability of the precipitate.

In the current work, thermo-kinetic modelling of AW-6016 was performed using MatCalc 5.61 (rel 1.003). The thermodynamic and diffusion information of solute elements and precipitate phases to set-up the system of matrix and precipitates were read from the thermodynamic data base (mc_al2.010.tdb) and diffusion data base (mc_al_2.001.ddb). Metastable and stable precipitates considered in the modelling were disordered $\mathrm{Mg}-\mathrm{Si}$ co-clusters, coherent ordered Al-containing GP zones, semi-coherent needle-like $\beta$ " (Mg5Si6), semi-coherent rod-like $\beta$ ' and in-coherent $\beta$-Mg2Si 
and Si. Dislocation density, grain size, Young's modulus of the matrix, volumetric misfit, the shape of the different precipitates and nucleation site preferences were taken from the work of Lang et al. [6]. Their work simulated the DSC-curves of different AW-6xxx alloys during continuous heating after solution heat treatment and quenching using the software, MatCalc. In the current work the yield strength of the material during ageing was computed using physical models that take into account intrinsic grain boundary, solid solution and precipitate strengthening contributions. These physical models for yield strength are included in the MatCalc software [15].

\section{Results and Discussion}

In order to calibrate the MatCalc precipitation kinetic model, DSC tests were performed in the $\mathrm{T} 4$, W-temper and $\mathrm{W}+205{ }^{\circ} \mathrm{C} / 1 \mathrm{~h}$ tempers. Fig. 3 (a) shows the DSC curve of the as-delivered (T4 temper) sheet. During the start of heating, an endothermic peak appears around $200{ }^{\circ} \mathrm{C}$ relating to the dissolution of GP Zone precipitates and infers these precipitates were present in the as-received AW-6016-T4 sheet [16]. An early exothermic peak appears around $80{ }^{\circ} \mathrm{C}$ in the DSC curves of the $\mathrm{W}$ temper sample relating to the precipitation of Mg-Si co-clusters or GP Zones. This confirms the super saturated solid solution state characteristic of W-tempers. The artificial ageing of $\mathrm{W}$ temper at $205^{\circ} \mathrm{C}$ for $1 \mathrm{~h}$ led to precipitation of the $\beta^{\prime \prime}$ phase and this was confirmed from the DSC curve with an endothermic peak indicating their dissolution at around $255^{\circ} \mathrm{C}$.
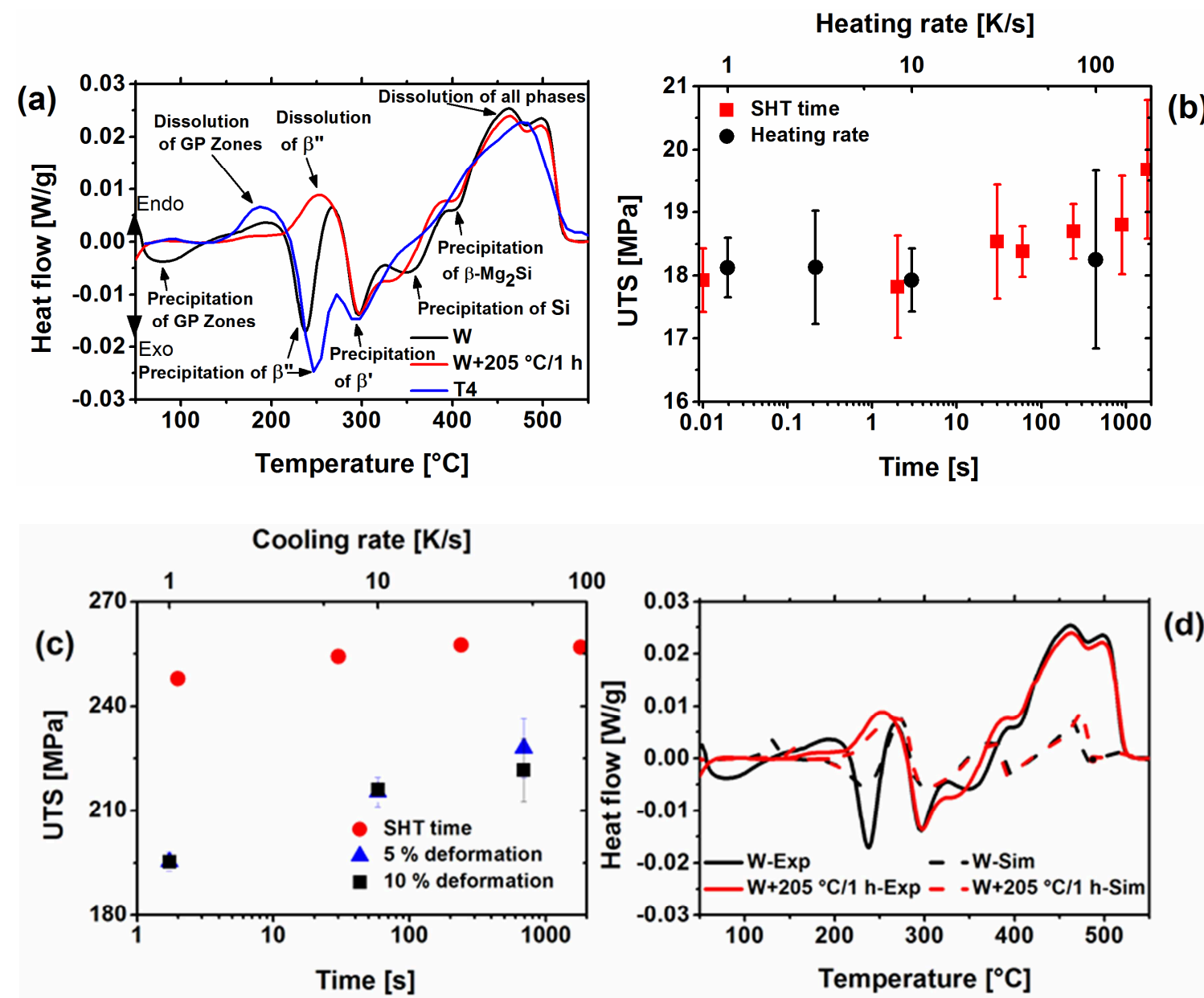

Fig. 3. (a) DSC curves of the AW-6016 alloy in $\mathrm{T} 4, \mathrm{~W}$ and $\mathrm{W}+205^{\circ} \mathrm{C} / 1 \mathrm{~h}$ tempers. (b) Ultimate tensile strength measured at $560{ }^{\circ} \mathrm{C}$ of AW-6016-T4 sheet for different heating rates and SHT times. (c) Ultimate tensile strength of paint baked AW-6016-T4 sheet after SHT for different times as well as after SHT + deformation + quenching at different cooling rates. (d) Simulated DSC curves from MatCalc compared with experimental DSC curves. 
In order to optimize the heating rate, solution heat treatment (SHT) time and SHT parameters the ultimate tensile strength was measured (Fig. 3(b)). Heating rates were selected within the range 1$100 \mathrm{~K} \mathrm{~s}^{-1}$ to accommodate existing heating technologies, such as convection oven, plasma, infrared, contact, induction and laser heating. It can be seen the heating rate has no significant effect on the UTS values implying the optimum selection of heating rate should be based on ease of equipment integration and reduction of processing time. There was a slight increase in average UTS values from 18 to $19.5 \mathrm{MPa}$ with increasing SHT time from $30 \mathrm{~s}$ to $30 \mathrm{~min}$, but this increase was within the measurement error.

To better understand the effect of SHT time, UTS values were measured at the end of the process chain (i.e., after SHT + quenching + paint baking at $185^{\circ} \mathrm{C} / 20 \mathrm{~min}$ (Fig. 3(c))). The UTS values after paint baking increased with increasing SHT time up to $4 \mathrm{~min}$. There was no significant increase in UTS after 4 min. This means that GP Zone precipitates in the AW-6016-T4 sheet dissolved completely after $4 \mathrm{~min}$ of SHT time bringing all $\mathrm{Mg}$ and $\mathrm{Si}$ atoms into solution. These solutes were responsible for the formation of the hardening phase, $\beta^{\prime \prime}$, during paint baking.

Deformation was introduced before quenching of the AW-6016 sheet. It is clear from Fig. 3(c) that increasing deformation from $5 \%$ to $10 \%$ early in the process chain slightly decreases the UTS values by $\sim 3 \%$ after the paint baking step, but only for the highest cooling rate. This may be related to the annihilation of vacancies at dislocations during quenching reducing nucleation sites. However, it needs further investigation.

Evolution of the precipitate microstructures in AW-6016 alloy in $\mathrm{W}$ and $\mathrm{W}+205^{\circ} \mathrm{C} / 1 \mathrm{~h}$ tempers was derived from the respective DSC curves (Fig. 3(a)). This was observed by the appearance of either endothermic or exothermic peaks. The individual peaks identified in a differential scanning calorimetry (DSC) analysis can be attributed to the nucleation, growth and dissolution of certain types of precipitates. A thermo-kinetic simulation of these DSC curves was performed in MatCalc and is presented in Fig. 3(d). It is clear from the location of the peaks in the simulated DSC curves that evolution of endothermic and exothermic peaks during continuous heating is very similar to the experimental DSC curves. From this it is shown that the present simulation framework is capable of describing the decomposition of the supersaturated matrix, involving the formation and identification of the most relevant metastable and stable precipitates as shown in Fig. 4 (a). It can be seen from the simulation that during start of heating in the DSC, formation of GP Zone and dissolution of $\beta^{\prime \prime}$ occurs in the case of $\mathrm{W}$ and $\mathrm{W}+205^{\circ} \mathrm{C} / 1 \mathrm{~h}$ tempers. This validated the precipitation state of the tempers.
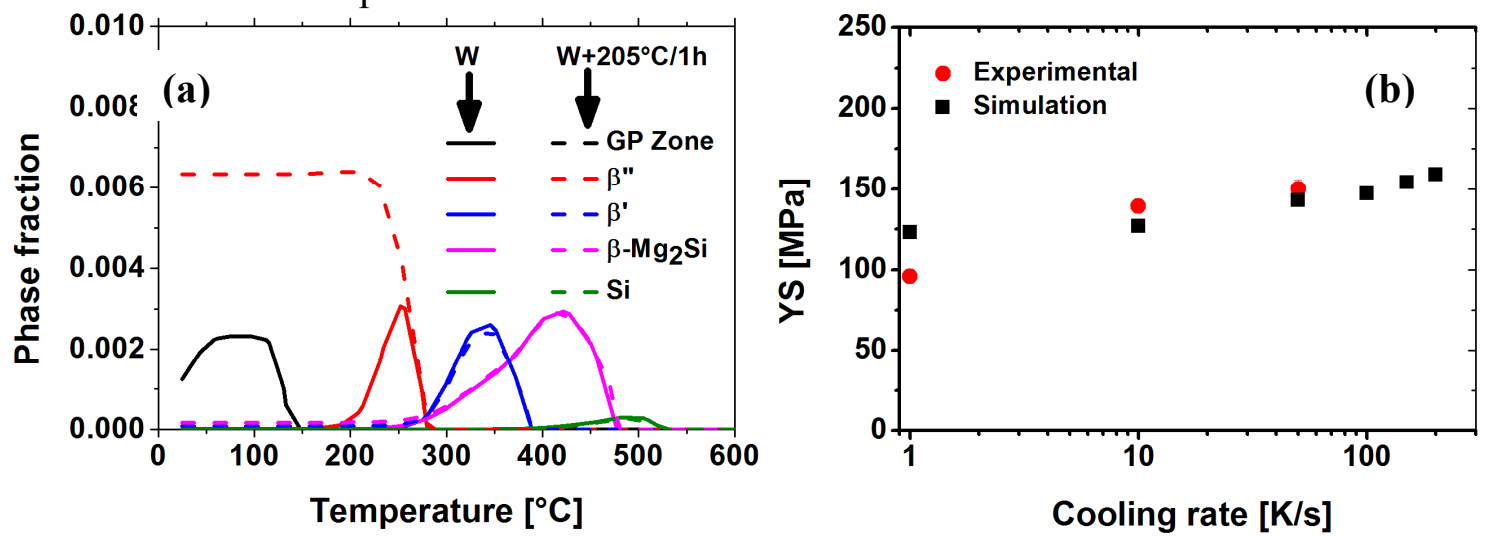

Fig. 4. (a) Simulated molar phase fraction of the phases involved during heating in the DSC. (b) Simulated and experimental Yield strength values after paint baking as a function of cooling rate during quenching.

After SHT, quenching is the next important parameter for the simultaneous hot stamping and quenching process. Rapid cooling freezes more solutes and vacancies in the Aluminium matrix and contributes to the formation of the hardening phase, $\beta^{\prime \prime}$. Yield strength values after paint baking increases with increasing cooling rate as shown in Fig. 4(b). There is an acceptable level of prediction of yield strength values from MatCalc simulation as compared with the experimental values. 


\section{Summary}

The simultaneous hot stamping and quenching process for AW-6016-T4 sheet was analysed to understand the influence of the heating rate, SHT time, deformation and cooling rate process parameters on the final mechanical properties. It was found the heating rates between 1 and $100 \mathrm{~K} \mathrm{~s}^{-1}$ have no significant effect on the processing. At least $4 \mathrm{~min}$ of SHT time is required to achieve the highest strength at the end of the process chain. Increasing the deformation and cooling rates was found to have positive effect on the paint bake response. These observations were complemented by the thermo-kinetic simulation of the DSC curves and yield strength of AW-6016 alloy using MatCalc.

\section{Acknowledgement}

The authors would like to gratefully acknowledge the Austrian Federal Ministry for Transport, Innovation and Technology (BMVIT) and the federal state of Upper Austria for funding this research work within the frame work of Independent research UF2015.

\section{References}

[1] R.P. Garrett, J. Lin, T.A. Dean, Solution Heat Treatment and Cold Die Quenching in Forming AA 6xxx Sheet Components: Feasibility Study, 8 (2005) 673-680. doi:10.4028/www.scientific.net/AMR.6-8.673.

[2] M. Kumar, N. Sotirov, C. Chimani, Characterization of High Strength Al-Zn-Mg Alloy Sheet for Hot Stamping, Mater. Sci. Forum. 794-796 (2014) 796-801. doi:10.4028/www.scientific.net/MSF.794-796.796.

[3] A. Falahati, E. Povoden-Karadeniz, P. Lang, P. Warczok, E. Kozeschnik, Thermo-kinetic computer simulation of differential scanning calorimetry curves of AlMgSi alloys, Int. J. Mater. Res. 101 (2010) 1089-1096. doi:10.3139/146.110396.

[4] A. FAlAHATI, J. WU, P. LANG, M.R. AHMADI, E. POVODEN-KARADENIZ, E. KOZESCHNIK, Assessment of parameters for precipitation simulation of heat treatable aluminum alloys using differential scanning calorimetry, Trans. Nonferrous Met. Soc. China. 24 (2014) 2157-2167. doi:10.1016/S1003-6326(14)63327-6.

[5] P. Lang, T. Wojcik, E. Povoden-Karadeniz, A. Falahati, E. Kozeschnik, Thermo-kinetic prediction of metastable and stable phase precipitation in Al-Zn-Mg series aluminium alloys during non-isothermal DSC analysis, J. Alloys Compd. 609 (2014) 129-136. doi:10.1016/j.jallcom.2014.04.119.

[6] P. Lang, E. Povoden-Karadeniz, A. Falahati, E. Kozeschnik, Simulation of the effect of composition on the precipitation in 6xxx Al alloys during continuous-heating DSC, J. Alloys Compd. 612 (2014) 443-449. doi:10.1016/j.jallcom.2014.05.191.

[7] J. Svoboda, F.D. Fischer, P. Fratzl, E. Kozeschnik, Modelling of kinetics in multi-component multi-phase systems with spherical precipitates I: Theory, Mater. Sci. Eng. A. 385 (2004) 166-174. doi:10.1016/j.msea.2004.06.018.

[8] E. Kozeschnik, J. Svoboda, F.D. Fischer, Modified evolution equations for the precipitation kinetics of complex phases in multi-component systems, Calphad Comput. Coupling Phase Diagrams Thermochem. 28 (2004) 379-382. doi:10.1016/j.calphad.2004.11.003.

[9] H.J. Rack, The influence of prior strain upon precipitation in a high-purity 6061 aluminum alloy, Mater. Sci. Eng. 29 (1977) 179-188. doi:10.1016/0025-5416(77)90125-2.

[10] P. Sherstnev, P. Lang, E. Kozeschnik, Treatment of Simultaneous Deformation and SolidState Precipitation in Thermo-Kinetic Calculations, Eccomas 2012. (2012) 8. 
[11] U.F. Kocks, Laws for Work-Hardening and Low-Temperature Creep, J. Eng. Mater. Technol. 98 (1976) 76. doi:10.1115/1.3443340.

[12] H.. Stüwe, Dynamische erholung bei der warmverformung, Acta Metall. 13 (1965) 13371342. doi:10.1016/0001-6160(65)90045-3.

[13] F.D. Fischer, J. Svoboda, F. Appel, E. Kozeschnik, Modeling of excess vacancy annihilation at different types of sinks, Acta Mater. 59 (2011) 3463-3472. doi:10.1016/j.actamat.2011.02.020.

[14] P. Lang, A. Falahati, R. Radis, M.R. Ahmadi, P. Warczok, E. Kozeschnik, Modelling the Influence of Cooling Rate on the Precipitate Evolution in Al-Mg-Si (Cu) Alloys, in: Mater. Sci. Technol. (MS\&T), 16.-20.10.2011, 2011: pp. 284-291.

[15] M.R. Ahmadi, E. Povoden-Karadeniz, L. Whitmore, M. Stockinger, A. Falahati, E. Kozeschnik, Yield strength prediction in Ni-base alloy 718Plus based on thermo-kinetic precipitation simulation, Mater. Sci. Eng. A. 608 (2014) 114-122. doi:10.1016/j.msea.2014.04.054.

[16] Y. Birol, Pre-straining to improve the bake hardening response of a twin-roll cast Al-Mg-Si alloy, Scr. Mater. 52 (2005) 169-173. doi:10.1016/j.scriptamat.2004.10.001. 